\title{
DA SOCIOLOGIA DA SOCIALIZAÇÃO À SOCIOLOGIA DA INDIVIDUAÇÃO CONTRIBUTOS PARA UMA SOCIOLOGIA DO TEMPO DOS INDIVÍDUOS
}

\author{
FROM THE SOCIOLOGY OF SOCIALIZATION TO THE \\ SOCIOLOGY OF INDIVIDUATION \\ CONTRIBUTIONS TO A SOCIOLOGY OF INDIVIDUAL TIME
}

\author{
João Eduardo Martins \\ Faculdade de Economia, Universidade do Algarve, \& Centro Interdisciplinar de Ciências Sociais (CICS.NOVA). \\ Campus de Gambelas, 8005-139 Faro, Portugal. Email: jrmartins@ualg.pt
}

\begin{abstract}
Resumo: Este artigo contribui para a discussão teórica em torno de uma sociologia dos indivíduos, num tempo societal marcado por uma forte individualização das relações sociais. Mobiliza-se o trabalho de três dos principais autores que se situam neste movimento teórico de uma sociologia à escala dos indivíduos, Bernard Lahire, François Dubet e Danilo Martuccelli, para fundamentar a pertinência heurística, no tempo dos indivíduos, de uma sociologia da individuação. Parte-se de uma crítica do que Martuccelli designa por sociologia da socialização para chegar a uma sociologia talhada para a compreensão sociológica dos desafios que os indivíduos enfrentam num mundo social em processo crescente de singularização societal.
\end{abstract}

Palavras-chave: sociologia da socialização, sociologia dos indivíduos, teorias sociológicas, individuação.

\begin{abstract}
This article contributes to the theoretical discussion around a sociology of individuals, in a societal time marked by a strong individualization of social relations. The work of three leading authors of an individual-scale sociology, Bernard Lahire, François Dubet and Danilo Martuccelli, is mobilized to substantiate the heuristic relevance of a sociology of individuation, in the time of individuals. It starts with a critique of what Martuccelli calls sociology of socialization to arrive at a sociology tailored to the sociological understanding of the challenges individuals face in a social world of growing societal singularization.
\end{abstract}

Keywords: sociology of socialization, sociology of individuals, sociological theories, individuation.

\section{Introdução}

Procura-se neste texto fazer uma discussão teórica fundada na ideia de que num tempo marcado por uma forte individualização das relações sociais e da sociedade singularista (Martuccelli, 2010a), a sociologia precisa de renovar os seus quadros conceptuais para dar conta da inteligibilidade do social à escala individual.

Parte-se da proposta teórica em torno da ideia de crise da ideia de sociedade $^{1}$ e da dissociação entre o actor e o sistema (Dubet, 1996), para questionar o modelo analítico clássico na sociologia, centrado numa sociologia da socialização² e 
no modelo do personagem social, que privilegiou na história da sociologia um modo de explicação sociológico centrado na relação entre o espaço das posições sociais e o espaço das representações sociais e das tomadas de posição, de que uma sociologia das classes sociais é o seu melhor exemplo.

Quando se diz que a sociologia precisa renovar os seus quadros conceptuais para dar conta da inteligibilidade do social à escala individual tem-se como pressuposto que na segunda modernidade (Beck, 1992) ou modernidade tardia (Giddens, 1998) há uma nova maneira de fazer a sociedade e de produção dos indivíduos, com uma injunção societal a que os indivíduos sejam autores da sua vida (Dubet, 1996). Este individualismo institucional, segundo Beck (1992), faz com que numa sociedade de risco marcada pela incerteza e pela ambivalência, os indivíduos procurem encontrar soluções biográficas para fazer face a contradições sistémicas.

Não se trata de renegar os contributos da sociologia naquilo que os seus quadros teóricos foram desenvolvendo ao longo da sua história e que a aproximaram do que hoje se designa por sociologia dos indivíduos. Se em Weber (1971) a preocupação era com o sentido da acção social e de alguma forma a sociologia compreensiva pode ser vista como uma das primeiras abordagens percursoras de uma sociologia dos indivíduos, a sua preocupação primeira era com a intersubjectividade como aspecto fundamental da construção da relação social.

Também Simmel (1999) pode ser encarado como um autor que já apresenta a importância da individualidade nas sociedades modernas quando fazia depender a construção dos indivíduos da crescente complexidade dos círculos sociais inerentes ao desenvolvimento das sociedades modernas. As correntes teóricas preocupadas com uma leitura à escala microsocial; a dramaturgia social goffmaniana, $\mathrm{o}$ interacionismo simbólico, a etnometodologia e a fenomenologia social, preocuparam-se sobretudo com as interacções e as intersubjectividades que fabricam a ordem social (Corcuff, 1997, Le Breton, 2004).

Todas estas propostas teóricas que reemergem nos anos 80 do século passado (Touraine, 1996) em oposição às leituras sistémicas, seja na forma do estruturalismo, do estrutural-funcionalismo ou das mais diversas formas de funcionalismo, permitem uma aproximação forte ao mundo vivido dos actores sociais mas não podíamos estar mais de acordo com Martuccelli e de Singly (2012, p. 29) quando nos dizem, referindo-se ao tipo de sociologia predominante na primeira modernidade que,

Nenhum outro modelo resume melhor o projecto sociológico da primeira modernidade que a noção do "personagem social". Ela designa a vontade de tornar inteligíveis as acções e as experiências do indivíduo em função da posição social. Cada indivíduo ocupa uma posição e esta posição faz dele um exemplar único e típico. Ele encontra-se submergido nos espaços sociais que originam, através de um conjunto de 
forças sociais, as suas condutas e experiências. Esta equação funda o coração do saber profissional partilhado pelos sociólogos fazendo compreender os traços individuais como factores derivados de uma inscrição social particular. Neste período, apesar da sua diversidade, todas as abordagens partilham este modelo geral que faz da posição do actor o melhor - senão o único - operador analítico para dar conta das suas maneiras de ver, de agir e de perceber o mundo. Nada de espantar se no centro deste modelo, um papel maior é dado ao processo de socialização. Sublinhemos que o triunfo do modelo do personagem social não significa nunca a liquidação do indivíduo, mas a imposição hegemónica de um tipo particular de leitura.

No nosso texto não se trata de recusar a existência de quadros conceptuais no património histórico da sociologia que possam contribuir para uma sociologia dos indivíduos. Trata-se de defender que o modelo hegemónico identificado por Martucelli de uma sociologia posicional (uma sociologia que confere primazia explicativa às posições dos agentes sociais no mundo social) não é a única forma legítima de fazer sociologia e que na segunda modernidade em que se constata empiricamente a individualização das relações sociais na família, na escolarização, no trabalho, na política e em tantas outras esferas da vida social cremos que nem é a mais frutífera do ponto de vista sociológico para fazer uma sociologia à escala dos indivíduos.

É essa a proposta de autores como Martuccelli (2006), de Singly (2006), Beck (1992), Lahire (2003), Dubet (1996) entre muitos outros que se situam neste tipo de sensibilidade sociológica mas que diferem nas suas formas de dar conta de como se produzem socialmente os indivíduos. Trata-se, portanto, de fazer a defesa da necessidade de uma sociologia dos indivíduos que não descure aquilo que consideramos uma matéria-prima essencial da análise sociológica, as existências individuais dos actores sociais, as suas subjectividades, as suas maneiras de pensar, sentir e agir, inclusivamente, nas formas mais íntimas da sua vivência social, e que permita a partir daí, fazer uma leitura do social à escala macrossociológica. É a partir da defesa desta ideia que vamos pôr em debate os contributos de alguns dos principais autores contemporâneos que podemos inserir neste movimento de uma sociologia dos indivíduos (Martuccelli e de Singly, 2012), para percebermos algumas das diferenças e especificidades das suas propostas e dos seus diferentes modos de inteligibilidade do social.

Parte-se de uma crítica a uma sociologia da socialização, com ênfase no estruturalismo construtivista de Pierre Bourdieu, para chegar à sociologia da individuação ${ }^{3}$ de Danilo Martuccelli, mobilizando para o debate ainda a teoria do actor plural de Bernard Lahire e sociologia da experiência de François Dubet, com o enfoque no conceito de experiência social. O movimento teórico da sociologia dos indivíduos sistematizado por Martuccelli e de Singly (2012) na obra As Sociologias do Indivíduo. Domínios e Abordagens, traça um panorama do que os autores designam 
por sociologias do indivíduo, mas deixa bem claro as diferenças entre os diferentes corpus teóricos que se situam neste modo de olhar o social. Se todas as perspectivas se aproximam neste reconhecimento da importância de colocar os indivíduos no centro do projecto sociológico, elas diferenciam-se claramente nos modos teóricos e metodológicos de analisar o social e a fabricação social dos indivíduos. No que se refere aos autores que referenciamos no texto para a construção do nosso argumento podemos dizer que há claras diferenças nos modos de dar inteligibilidade ao social nas propostas de Lahire, Dubet e Martuccelli.

Com Lahire (2003) temos uma sociologia à escala individual, que se caracteriza, no dizer do próprio, por ser uma sociologia contextualista e disposicionalista que partindo de uma crítica ao conceito de habitus e dos campos de Pierre Bourdieu, complexifica a sua análise com a busca das variações intraindividuais e interindividuais dos actores plurais e na compreensão de como se constroem os seus patrimónios individuais de disposições. Em Dubet (1996), a centralidade na sua sociologia da experiência é dada ao conceito de experiência social e à forma como os actores se constroem, num mundo social cada vez mais heterogéneo e fragmentado, a partir de lógicas de acção não poucas vezes contraditórias. É da capacidade dos indivíduos articularem de forma combinada a lógica da integração, a lógica da estratégia e a lógica da subjectivação, que eles se produzem como autores das suas vidas. Em Martucelli (2006), a sua sociologia da individuação 4 tem como centralidade o conceito de épreuve como operador analítico fundamental da sua leitura do social e estamos em presença de uma macrossociologia que partindo das existências individuais e da compreensão de como os indivíduos enfrentam o mundo social, procura tornar inteligível uma determinada singularidade societal.

\section{A sociologia da socialização}

Segundo Martuccelli (2005, p. 4) ao longo da história da Sociologia, o estudo do indivíduo, efectua-se a partir de três grandes perpectivas em que cada uma delas se caracteriza por um nó problemático específico. A sociologia da socialização, a sociologia da subjectivação e a sociologia da individuação. A sociologia da socialização, que Martuccelli (2006) diz ter predominado na sua forma hegemónica na sociologia clássica, faz recurso a um modo de inteligibilidade do social em que a produção e a reprodução da ordem social se conceptualiza a partir da relação entre o espaço das posições sociais e o espaço das representações e das práticas sociais e parte do pressuposto de uma elevada correspondência entre estes dois espaços de relação.

Uma obra paradigmática a este nível é La Distinction de Bourdieu (1979) que faz depender os gostos e os estilos de vida das diferentes posições ocupadas pelos 
agentes sociais na estrutura do espaço social. Para Pierre Bourdieu (1980) a socialização caracteriza-se pela formação do habitus e é este o operador conceptual que permite, por um lado, a compreensão e explicação dos mecanismos de produção e de reprodução do social e por outro lado, as estratégias dos agentes sociais;

\begin{abstract}
Os condicionamentos associados a uma classe particular de condições de existência produzem os habitus, sistemas de disposições duráveis e transponíveis, estruturas estruturadas dispostas a funcionar como estruturas estruturantes, quer dizer como princípios geradores e organizadores de práticas e representações que podem ser objectivamente adaptadas ao seu fim sem supor a visão consciente dos fins e do domínio expresso das operações necessárias para as satisfazer, objectivamente "reguladas" e "regulares" sem ser em nada o produto da acção organizada de um chefe de orquestra. (Bourdieu, 1980, pp. 88-89)
\end{abstract}

É a célebre trilogia, estruturas, habitus, práticas. A fórmula que permite o desenho conceptual do estruturalismo construtivista de Bourdieu. Se a proposta teórica de Bourdieu é um bom exemplo do que Martuccelli designa por sociologia da socialização, as visões funcionalistas da sociologia clássica, quer na sua versão Durkheimiana ${ }^{5}$ com a sua tónica nos constrangimentos sociais e na exterioridade dos factos sociais (Durkheim, 1897; 1967) que se impõem aos indivíduos, quer na versão estrutural-funcionalista de Talcott Parsons, com o seu complexo modelo explicativo AGIL (Parsons, 1977), remetem para concepções hipersocializadas de actor social, onde é dado pouco espaço aos indivíduos como autores de si na construção do social. Nas versões teóricas mais extremas, elas são mesmo acusadas de reproduzirem uma concepção de ator social que não passaria de um mero idiota cultural (Coulon, 1987), pelo seu papel na reprodução do sistema social. O mesmo poderíamos dizer das propostas marxistas e neo-marxistas, onde a compreensão da acção dos indivíduos remete necessariamente para o seu lugar nas relações sociais de produção (Marx e Engels, 2008) ou nas suas versões mais complexas e menos dicotómicas, para o lugar ou fracção de classe (Wright, 2013) ocupado na estrutura das relações sociais.

\title{
Contributos para uma sociologia à escala individual
}

Os contributos do sociólogo Bernard Lahire (2003) têm uma enorme relevância para a sociologia dos indivíduos, quer de um ponto de vista teórico, quer do ponto de vista metodológico (com o recurso à construção de retratos sociológicos dos indivíduos (Lahire, 2002; Lopes, 2012), uma vez que a sua teoria do actor plural, apesar de continuar dentro do paradigma da sociologia disposicional, produz, para utilizar as palavras do próprio, uma sociologia à escala individual. Bernard Lahire 
assenta a sua teoria numa crítica teórica e empírica da teoria do habitus e dos campos de Pierre Bourdieu e elabora uma sociologia disposicional que leva em conta a multiplicidade de contextos de socialização que condicionam o agir, o pensar e o sentir dos indivíduos sociais (Lahire, 2003, 2013).

A sua teoria é assim uma teoria do actor plural que leva em conta como cada ser humano constrói socialmente o seu património individual de disposições. Para este sociólogo não existe um habitus homogéneo e unificador universalizante que seria definidor e classificador de todas as práticas e disposições dos agentes sociais em todas as situações e campos onde os indivíduos agem (Lahire, 2005, p. 24). Fala-nos antes de uma pluralidade e heterogeneidade de disposições incorporadas por cada agente social nas sociedades de forte diferenciação social, em que a família se transformou num agente de socialização primária em concorrência com outros agentes pela legitimidade da sua educação. Cada vez mais cedo a socialização dos indivíduos é atravessada por contextos de socialização múltiplos e plurais que participam da sua produção.

A educação de infância e o pré-escolar estão cada vez mais generalizados nas populações do mundo dito ocidental. As crianças e os jovens são cada vez mais cedo expostos aos efeitos socializadores da sociedade em rede (Castells, 2012), uma prática desportiva e cultural institucionalizada atravessa hoje desde cedo a vidas dos indivíduos e das famílias. A sociedade de consumo condiciona de forma forte a vida individual e societal. Um dos argumentos fortes que desenvolve na sua obra O Homem Plural (2003) é que se definirmos o habitus como um sistema homogéneo de disposições gerais, permanentes, transferíveis e transponíveis de uma situação para outra, de um domínio de práticas para outro, isso significa que cada vez menos agentes das nossas sociedades podem ser definidos a partir de um tal conceito.

Uma definição desse tipo convém melhor para a compreensão sociológica de sociedades homogéneas, demograficamente frágeis, com extensão geográfica relativamente pequena, que proporcionam esquemas socializadores relativamente estáveis e coerentes para os seus membros (Lahire, 2003, p. 34). Precisamente o caso do dos Cabila, na Argélia, no tempo em que Bourdieu se dedicou a estudar esta sociedade. Segundo Lahire, nas sociedades em que as crianças conhecem muito cedo uma diversidade de contextos socializadores, os patrimónios individuais de disposições raramente são muito coerentes e homogéneos. Os esquemas de socialização em sociedades diferenciadas são cada vez mais heterogéneos e precoces, e as disposições não são universalmente transponíveis, mas actualizadas sob condição, consoante as situações, os contextos de acção e os universos sociais por onde circulam os actores.

Para Lahire deduzir apressadamente da análise das práticas de um indivíduo, ou de um grupo social, num contexto social determinado, esquemas ou 
disposições gerais, habitus, que funcionariam da mesma maneira em qualquer lugar, em outros lugares e circunstâncias, constitui um erro de interpretação sociológica. O habitus deve ser assim posto à prova da investigação empírica (Lahire, 2005, p. 27) e deve ser feita a análise sociológica dos elementos que são pretensamente transferíveis de um contexto social para outro. É a análise empírica que deve responder à transponibilidade e à transferibilidade (ou não) do conjunto de disposições adquiridas num determinado contexto de socialização.

Bernard Lahire procura assim estudar o social individualizado, o social refractado, incorporado e interiorizado num corpo individual, que tem a particularidade de atravessar instituições, grupos, campos de forças e de lutas ou cenas diferentes (Lahire, 2003). Trata-se de reconhecer que o indivíduo é produto de múltiplos e complexos processos de socialização e isso implica a análise teórico-empírica dos contextos em que os indivíduos constroem e actualizam essas mesmas disposições. Este programa sociológico que procura apreender as variações intraindividuais e interindividuais do comportamento dos actores sociais, $\mathrm{o}$ mesmo é dizer, a pluralidade interna dos indivíduos nas múltiplas inscrições contextuais da acção implica exigências metodológicas novas (Lahire, 2005, p. 27).

Para apreender esta pluralidade interna e a maneira como ela age e se distribui segundo os diversos contextos sociais, é necessário dotarmo-nos de dispositivos metodológicos que permitam observar directamente ou reconstruir indirectamente, através de diversas fontes, a variação contextual dos comportamentos individuais.

A sociologia à escala individual é deste modo um programa científico inovador que procura interrogar-se sobre as maneiras como a pluralidade dos mundos e das experiências se incorporam no seio de cada indivíduo, observando a sua acção sobre uma diversidade de cenas no mundo social. Esta maneira de fazer a sociologia permite-nos perceber que os actores são plurais e que cada um deles é multissocializado e multideterminado e que os indivíduos não são um mero produto homogéneo da incorporação das estruturas objectivas do mundo social cujo habitus estaria na mais perfeita correspondência subjectiva à maneira da incorporação do social "da necessidade feita virtude" (Bourdieu, 1979).

De toda a forma, a maior ou menor unicidade do habitus e a aquisição de disposições homogéneas e coerentes, ou pelo contrário, plurais e heterogéneas, deve ser respondida pela investigação empírica, o que supõe que o habitus mais do que pressuposto a priori deve ser antes de mais nada posto à prova da empiria. Lahire (2013) dá assim um passo em frente com a sua crítica à teoria do habitus de Bourdieu, uma vez que se para este último autor é o habitus de classe que funciona como elemento explicativo por excelência das dinâmicas de reprodução da ordem social (Bourdieu e 
Passeron, 1964, 1970), com Lahire, a sociologia à escala individual introduz uma maior complexidade interpretativa e explicativa na leitura científica do funcionamento do social. Os patrimónios individuais de disposições são imprescindíveis na análise.

\section{A sociologia da experiência de François Dubet}

Partindo de uma crítica sociológica à sociologia dita clássica saída da modernidade, principalmente aquela que dominou o pensamento sociológico até ao fim da segunda guerra mundial, François Dubet, professor na Universidade de Bordéus, referindo-se à fragmentação do campo sociológico salienta que;

A extrema diversidade dos modelos, dos métodos e dos objectos, resulta do estilhaçamento de uma sociologia "clássica" que poderíamos identificar, em larga medida, e não sem arbitrariedade, com as obras de Durkheim e de Parsons tal como a apresentação que Nisbet fez da tradição sociológica. (Dubet, 1996, pp. 11-12)

Refere Dubet (1996, pp. 12-14) que no âmbito da sociologia clássica o actor individual é definido pela interiorização do social, sendo o indivíduo tanto mais autónomo quanto mais socializado estiver. Segundo este autor, o actor e o sistema separam-se; com o estilhaçamento da sociologia, a imagem clássica da sociedade desfaz-se e a unidade do actor e do sistema deixa de ser concebível quando a unidade funcional e cultural das sociedades deixa de ser reconhecida. Dubet propõe assim o conceito de experiência social para designar; "As condutas individuais e colectivas dominadas pela heterogeneidade dos seus princípios constitutivos, e pela actividade dos indivíduos que devem construir o sentido das suas práticas no próprio seio desta heterogeneidade" (Dubet, 1996, pp. 15).

São três as características essenciais do conceito de experiência. A primeira característica é a heterogeneidade dos princípios culturais e sociais que organizam as condutas. Como refere o autor, tudo se passa como se os actores adoptassem simultaneamente vários pontos de vista, como se a identidade fosse apenas o jogo movediço das identificações sucessivas, como se outrem fosse alternadamente definido de múltiplas maneiras, aliado e adversário, vizinho e exótico. Os indivíduos já não se conformam somente aos papéis e posições sociais prescritos no seio da vida social. Cabe-lhes reinventar a sua coerência pessoal e social a partir de lógicas de acção múltiplas e heterogéneas. Como refere Dubet (1996, p. 16): “Assim, a identidade social não é um 'ser', mas um 'trabalho'".

A segunda característica tem que ver com a relação subjectiva que os indivíduos mantêm em relação aos sistemas nos quais estão inseridos. Como a experiência é 
plural e as lógicas de acção são heterogéneas: “Os indivíduos não podem aderir totalmente a papéis e a valores que não têm já necessariamente coerência interna, eles não se 'colam' às suas personagens" (Dubet, 1996, p. 17). A pluralidade da experiência gera uma distância e um desprendimento. A experiência social é vivida como problema e ela torna cada indivíduo em autor da sua própria experiência. A terceira característica remete-nos para a rejeição da noção de alienação tão cara à tradição sociológica Marxista. A experiência colectiva é construída e os grandes projectos sociais unificantes e unificadores deixam de fazer sentido.

Para Dubet (1996, p. 95): “A noção de experiência só tem sentido e utilidade se a acção não for redutível à versão subjectiva do sistema, se o actor não estiver totalmente socializado". Assim sendo, a experiência social é construída, crítica e tem por objecto a subjectividade dos actores sociais. Esta sociologia compreensiva exige a dupla recusa da imagem de um actor totalmente cego ou totalmente clarividente. A posição escolhida assenta menos num postulado ontológico relativo à condição humana do que numa necessidade de método, porque a subjectividade dos actores, a consciência que eles têm do mundo e deles próprios, é a matéria essencial de que dispõe a sociologia da acção. A sociologia da experiência tem em vista definir a experiência como uma combinação de lógicas de acção, lógicas que ligam o actor a cada uma das dimensões de um sistema. O actor é obrigado a articular lógicas de acção diferentes e é a dinâmica gerada por esta actividade que constitui a subjectividade do actor e a sua reflexividade (Dubet, 1996, p. 107).

A experiência social resulta da articulação de três lógicas de acção. A lógica da integração; a lógica da estratégia e a lógica da subjectivação. Na lógica da integração, o actor define-se pelas suas pertenças. Na lógica da estratégia, o actor age tendo em conta os seus interesses numa sociedade concebida como um mercado. Na lógica da subjectivação, o actor representa-se como um sujeito crítico que se posiciona face a um sistema de dominação (Dubet, 1996, p. 113).

A lógica da integração remete-nos para uma identidade integradora;

A identidade do actor é definida como sendo a vertente subjectiva da integração do sistema. A identidade é tão só a maneira como o actor interiorizou os valores institucionalizados por meio dos papéis. O indivíduo define-se e "apresenta-se" aos outros pela sua pertença, pela sua posição, por aquilo que ele vive, ele próprio como um "ser", frequentemente como uma herança. Neste registo da acção, a personalidade está mais perto da personagem social. O indivíduo incorporou as expectativas de outrem no decurso de uma socialização primária, infantil e profunda, transformando mesmo esta identidade numa espécie de natureza quando ela diz respeito à língua e à nação, ao sexo, à religião, à classe social. (Dubet, 1996, p. 115) 
Na lógica da estratégia, a identidade é vivida como recurso. Sobre esta lógica de acção esclarece-nos Dubet;

Na lógica da estratégia, as relações sociais são definidas em termos de concorrência, de rivalidade mais ou menos viva dos interesses individuais ou colectivos. A linguagem dos actores é a da estratégia, do desporto, do jogo, dos ataques, dos adversários ou dos aliados, mais frequentemente ainda dos associados rivais. A sociedade é vista como um sistema de trocas concorrenciais na competição para se obterem bens raros: o dinheiro, $\mathrm{o}$ poder, o prestígio, a influência, o reconhecimento (...) não é a guerra de todos contra todos, o jogo está regulado, só raramente ele é de soma nula. Os sociólogos utilizam também mais naturalmente a linguagem do jogo ou do mercado que a da guerra para descreverem estas relações com os outros. Pensemos sobretudo na sociologia da acção organizada proposta por Crozier e Friedberg (Dubet, 1996, pp. 124-125).

Na lógica da subjectivação, a identidade do sujeito pode ser vista como um empenhamento. O sujeito investe-se na construção de si, ele é o autor da sua própria vida;

Este empenhamento numa representação cultural do sujeito é vivido como um inacabamento, como uma paixão impossível e desejada que permite descobrir-se como o autor da sua própria vida, ainda que seja na amargura ocasionada pela impossibilidade de realizar plenamente esse projecto (...) A parte subjectiva da identidade percebe-se tanto no despreendimento como no empenhamento, porque a identificação com a definição cultural de um sujeito impede a adesão total ao EGO, ao Nós e aos interesses. Ela provoca uma reserva que impede o indivíduo de ser totalmente o seu papel e a sua posição, de ser a sua personagem social. (Dubbet, 1996, pp. 131-132)

Dubet alerta-nos também para o facto de que apesar da sociologia da experiência partir da subjectividade dos actores sociais, a experiência social não pode ser desligada dos sistemas de acção social onde a mesma está inserida. O actor constrói uma experiência que lhe pertence, a partir de lógicas de acção que não lhe pertencem. No sistema de integração é a socialização que assegura os processos de reprodução social e legitima a lógica da integração. Sob a forma de interiorização de normas e de valores sociais ou sob a forma de controlo social, é a socialização normativa que orienta as condutas sociais dos actores. É este sistema que assegura a adesão aos papéis sociais e os padrões de estabilidade normativa. No sistema de interdependência a racionalidade dos actores é limitada e nas relações entre actor e sistema falar-se-á de jogos de actores e relações de poder. O modelo sociológico aqui adoptado será o individualismo metodológico de Raymond Boudon (1977) complementado com a análise estratégica de Crozier e Friedberg (1977). No sistema de 
acção histórico que fundamenta a lógica da subjectivação, o actor pode afirmar-se como sujeito crítico. É a historicidade no sentido que lhe dá Touraine (1996) sob a forma de tensão dialéctica entre cultura e relações sociais, entre comunidade e mercado que permite aos actores darem significação às suas práticas numa constante reflexividade lutando contra a alienação e a dominação social. Podem surgir então os movimentos sociais constituindo-se a sociedade num sistema de acção histórico.

Recorda Dubet que não há unidade do social e que, portanto, cada lógica de acção remete para um sistema, para um modo de inteligibilidade do social que coexiste com outros modos de inteligibilidade. É o pluralismo do social que convida à diversidade de interpretações possíveis do mesmo.

\begin{abstract}
A heterogeneidade das lógicas de acção leva pois a conceber a sociedade como um conjunto desprovido de centro em que não existe regulação ao nível de toda a sociedade, sendo "aberta" à reunião dos seus elementos. Não há concordância entre a totalidade e o sentido subjectivo da experiência. Do mesmo modo que a experiência social é uma combinação de lógicas de acção cujo sentido vem do trabalho de um indivíduo, assim aquilo a que se chama "o sistema social" ou a "sociedade" é uma combinação de elementos cuja unidade resulta da capacidade política dos actores. (Dubet, 1996, p. 156)
\end{abstract}

A imagem da "sociedade" que nos dá Dubet é, portanto, uma imagem que está muito longe da visão integrada do social que nos deixaram os sociólogos clássicos nas suas concepções mais positivistas. Em Dubet o social e a experiência dos actores são fragmentados, portanto, a sua identidade pessoal e social, só pode ganhar coerência ao cabo de um trabalho dos actores sobre si mesmos e sobre o mundo em que vivem.

A identidade social não é um "dado" adquirido de uma vez por todas, resultante dos mecanismos de socialização primária, mas um "construído" social permanente, realizado a partir de lógicas heterogéneas de acção social. A identidade social é assim uma identidade-problema, onde os actores sociais se produzem a si mesmos numa actividade social constante, articulando as diferentes lógicas de acção, por vezes contraditórias e conflituais, dando a melhor apresentação de si e tornando-se autores das suas próprias vidas. A sociologia da experiência é assim uma sociologia compreensiva que parte da subjectividade dos actores sociais e que estuda as representações, as emoções, as condutas humanas e as maneiras como os actores as explicam. Estamos então perante uma sociologia da subjectividade, ou melhor, perante uma sociologia que procura objectivar as experiências subjectivas dos diversos actores sociais. 


\section{A sociologia da individuação de Danilo Martuccelli}

A sociologia da individuação é uma macrosociologia que levando muito a sério as existências individuais tem como finalidade última a compreensão, não dos indivíduos em si, mas das grandes transformações societais que ocorrem num determinado momento sócio-histórico. A sociologia da individuação parte do indivíduo como elemento central da análise, mas não é o mesmo que é o objecto último da análise sociológica (Martins, 2014, p. 93). Segundo Martuccelli (2006) e à semelhança das propostas de Dubet (1996) com a crise da ideia de sociedade, actor e sistema separam-se e já não são percebidos como mantendo uma relação de correspondência unívoca, tal como era característico da sociologia clássica.

Com o estilhaçamento desta última dá-se a refutação do modelo do personagem social e a recusa de um modelo analítico hegemónico na sociologia centrado sobre uma sociologia posicional. Com a tendência estrutural de subida da singularidade (Martins, 2014; Martuccelli, 2010a) dá-se uma passagem do reconhecimento sociológico do individualismo ao reconhecimento sociológico do singularismo. O singularismo vem pôr em prática uma nova dinâmica societal entre o singular e o comum. Dá-se então, segundo este autor, a necessidade sociológica de se reconhecer a singularização crescente das trajectórias e das existências individuais, e isto mesmo quando os actores ocupam posições sociais similares. Uma ideia forte também presente na sociologia da experiência de Dubet (1996). O conceito de prova (épreuve no original) é um operador analítico central desta proposta de interpretação teórica. Segundo a definição de Martuccelli: "As provas são os desafios históricos, socialmente produzidos, desigualmente distribuídos, que os indivíduos são constrangidos a enfrentar" (Martuccelli, 2006, p.12). As provas têm quatro grandes características:

a) Elas são inseparáveis de uma narrativa particular, a de pôr à prova, o que permite dar um espaço ao indivíduo na tradição sociológica;

b) Toda a prova aparece como um exame, um teste, com o qual cada um de nós se confronta e através do qual se efectua uma selecção social;

c) As provas designam os grandes desafios societais às quais são submetidos de maneira constrangente os indivíduos e que são variáveis em função das sociedades e dos períodos históricos;

d) É próprio de cada prova o desafiar a nossa resistência e as nossas capacidades de lhe fazer frente, o que remete para uma concepção particular de actor social (Martins, 2014; Martuceli, 2010a).

Na sociologia da individuação tal como proposta por Martuccelli (2006), o actor é aquele que tem a capacidade de agir de outra forma. É pelo agir face a uma prova 
que o indivíduo se singulariza. É dando uma resposta pessoal a uma prova comum que ele se torna um actor singular. O actor é também aquele que se mede em relação a um desafio. Face aos desafios históricos e sociais com que se defronta, comum a todos os indivíduos, o actor mede-se em relação a essa mesma prova comum. O actor é aquele que se sente no pôr à prova. Uma prova é sempre qualquer coisa que é sentida de forma "intíma", subjectiva, pelos actores sociais. O seu sentir através do vivido da situação, é o fundamental ponto de partida para a compreensão de uma determinada significação societal (Martins, 2014; Martuccelli, 2010a).

A prova é sempre enquadrada por uma determinada ecologia social. A capacidade de agir do actor não pode ser compreendida sem levar em conta a maleabilidade da vida social porque só esta permite perceber a capacidade dos actores serem capazes de agir de outra maneira. Martuccelli destaca a importância para a análise das provações o levar em conta as ecologias sociais, a partir das quais, os actores enfrentam o mundo social. A abordagem de uma sociologia da individuação a fim de ser operacional deve restringir-se a um número limitado de provas julgadas particularmente significativas face a uma determinada realidade histórica e social concreta. Uma sociologia da prova procura assim dar conta de um sistema estandardizado de provas pelos quais se constitui um modo de individuação, dando conta ao mesmo tempo da difracção normativa pelo qual o social é de forma plural apropriado pelos indivíduos.

São oito as principais provas que Martucelli identifica como centrais nas sociedades contemporâneas ocidentais, embora abra espaço para a compreensão sociológica de outras que possam ser importantes na estruturação societal e na vida dos indíviduos. Quatro provas institucionais, a escola, a família, o trabalho e o território. Quatro provas não institucionais que passam pela relação à História, aos colectivos sociais, a relação aos outros e ainda a relação consigo mesmo. Estas provas são variáveis consoante os diversos contextos temporais e espaciais em que se produzem e algumas destas provas que podem ser estruturantes da vida dos indíviduos em determinadas sociedades e em determinados períodos históricos e podem não o ser noutras (Martuccelli, 2010b).

A sociologia da individuação de Martuccelli (2006) procura assim a compreensão de como são fabricados os indivíduos num contexto de uma determinada singularidade societal e dar resposta empírica à questão do tipo de sociedade que produz determinado tipo singular de indivíduos sociais. Trata-se afinal, recuperando a célebre passagem de Mills $(1997$, p. 7) de "compreender o teatro alargado da história em função das significações de que ela se reveste para a vida interior e a carreira dos indivíduos". 


\section{Para concluir}

Norbert Elias na sua célebre obra A Sociedade dos Indivíduos (2004) faz-nos compreender que a produção societal dos indivíduos é uma invenção social que se acelera com as transformações da modernidade e do processo civilizacional. No contínuo identitário nós-eu, só recentemente na História da humanidade, os indivíduos se percebem mais perto do seu "eu" em detrimento do sentimento de pertencer ao "nós". A fusão do indivíduo à sua comunidade de pertença foi o que prevaleceu ao longo da História das sociedades ${ }^{6}$. A modernidade traz consigo um processo contínuo na construção da autonomia dos indivíduos de tal forma que na contemporaneidade é muito forte a representação social dos indivíduos separados do nós. Como refere Elias,

O facto de se atribuir um valor mais elevado àquilo que distingue as pessoas umas das outras, ou seja à sua identidade do Eu, do que aquilo que elas têm em comum, ou seja à sua identidade do Nós, é uma característica das sociedades mais evoluídas dos nossos tempos. A primeira, a identidade do Eu, prevalece sobre a identidade do Nós. A este respeito haveria ainda mais a dizer. Contudo, a tendência óbvia a favor do Eu neste tipo de equilíbrio Nós-Eu, a sua tendência óbvia a favor do Eu não é nada evidente. Em fases de evolução anteriores, a identidade do Nós tem, muito frequentemente, a primazia sobre a identidade do Eu. (Elias, 2004, p. 178)

E ainda,

O Estado Republicano da Roma Antiga é um exemplo clássico de uma fase de evolução em que a pertença à família, à tribo ou ao Estado, ou seja, a identidade do Nós do homem singular, tinha um peso bastante maior no equilíbrio Eu-Nós do que hoje. A identidade do Nós era, por isso, inseparável da imagem que as camadas que marcavam a língua tinham de uma pessoa singular. A ideia de um indivíduo não inserido em nenhum grupo, de uma pessoa tal e qual como ele ou ela é, quando despido de quaisquer referências ao Nós, atribuindo ao indivíduo, à pessoa singular, um valor tão alto que todas as referências ao Nós, portanto, a pertença ao clã, à tribo ou ao Estado, parecem ser de importância menor, era algo que, na prática social do mundo da antiguidade, se encontrava geralmente para além do horizonte. Por conseguinte, não existia, nas línguas clássicas, nenhum termo equivalente ao conceito de "indivíduo". (Elias, 2004, p. 179)

Tudo se passa como se os indivíduos virados para si mesmos pudessem viver separados dos contextos societais que participam da sua produção. Seja na família, na escola, no trabalho, na política e até na religião, as principais instituições sociais são hoje atravessadas por um forte movimento de individualização das relações sociais 
(Beck, 1992; Beck e Beck-Gernsheim, 2002) que transformam profundamente a relação dos indivíduos com as instituições, as próprias instituições e o social que resulta das suas dinâmicas. Face a transformações societais desta dimensão, na direcção de uma sociedade dos indivíduos, a sociologia não pode deixar de repensar os seus quadros analíticos para fazer a compreensão sociológica do social e dar conta da sua inteligibilidade. Se no contexto da primeira modernidade a sociologia deu primazia à compreensão explicativa da sociedade a partir das dinâmicas de classe, da forma como o programa institucional (Dubet, 2002) participou na fabricação da ordem social e ao funcionamento das grandes colectividades sociais, no tempo contemporâneo dos indíviduos, as diversas sociologias dos indivíduos podem ser uma resposta analítica adequada quer do ponto de vista teórico quer empírico para captar a complexidade que o mundo plural em que vivemos tem vindo a produzir.

É neste movimento teórico que se inserem os autores que atrás abordámos nalgumas das suas principais linhas de problematização teórica, seja através da sociologia à escala individual de Bernard Lahire, da sociologia da experiência de François Dubet ou da sociologia da individuação de Danilo Martuccelli. A proposta teórica deste último autor parece-nos muito interessante para a análise sociológica do tempo dos indivíduos uma vez que partindo das existências individuais e do modo como os indivíduos enfrentam as provações societais se trata de uma macrosociologia que não ignora as estruturas sociais ${ }^{7}$. Pondo a tónica na fabricação societal dos indivíduos permite uma compreensão à escala individual em que não são descuradas as desigualdades sociais, as classes sociais, os efeitos de género, de idade ou de etnia, as relações de poder societal e o modo como estes factores centrais na sociologia dita clássica influênciam as dinâmicas do viver social. Ao partir de uma entrada analítica pelas existências individuais isso permite a compreensão explicativa de como o social se difracta na vida dos indivíduos e como os indivíduos participam nos diversos modos de fazer a sociedade.

\section{Notas}

Por decisão pessoal, o autor do texto não escreve segundo o novo acordo ortográfico.

1 A crise de ideia de sociedade e a separação entre actor e sistema é bem trabalhada na obra de François Dubet $A$ Sociologia da Experiência (1996) (e posta à prova da empiria nos seus trabalhos de investigação sociológica) em que o autor faz uma crítica ao que designa de sociologia clássica e que identifica com as obras de Durkheim e Parsons (na visão apresentada por Robert Nisbet da tradição sociológica) e a sua sociologia da integração, em que a unidade do sistema e dos actores é representada como um unidade fundamental do todo social e que face à progressiva fragmentação da experiência e ao 
declínio do "programa institucional" (Dubet, 2002) já não permite dar conta do funcionamento disso a que os sociólogos se habituaram a chamar "sociedade". É a partir desta ideia que Dubet vai construir todo o seu edifício teórico no que vai designar por sociologia da experiência (Dubet, 1996).

2 A distinção entre uma sociologia da socialização e uma sociologia da individuação, é feita com suporte nos trabalhos teóricos e empíricos de Danilo Martuccelli, autor que se tem destacado numa sistematização rigorosa dos trabalhos sociológicos contemporâneos que se inserem numa sociologia dos indivíduos. Segundo Martuccelli (2006), autor com quem estamos em total acordo, aquilo que este designa por sociologia da socialização, remete para um modo de explicação sociológica que predominou na sociologia clássica, em que a sociologia de Durkheim com enfâse na ideia da exterioridade dos factos sociais; a sociologia à maneira de Parsons, com a primazia dada aos sistemas culturais no processo de socialização e na incorporação do social, ou mais recentemente a sociologia à maneira de Bourdieu, ilustram perfeitamente. A sociologia à la Bourdieu é um excelente exemplo de uma sociologia posicional que procura explicar as práticas, as representações sociais e as tomadas de posição dos agentes sociais a partir da posição que estes ocupam no espaço social. O recurso à obra La Distinction (1979) como ilustração deve-se ao facto desta obra tornar o social inteligível a partir da relação entre o espaço das posições sociais e o espaço dos estilos de vida. Em Bourdieu (1979), o seu estruturalismo construtivista conceptualiza a socialização a partir da dialéctica entre interiorização da exterioridade e da exteriorização da interioridade, o mesmo é dizer, entre as estruturas objectivas do mundo social e as representações subjectivas, sendo o sentido prático (1980) resultado de um habitus incorporado a partir das condições objectivas de existência e das trajectórias dos agentes sociais. São sempre agentes sociais socializados num determinado ponto do espaço social e numa dada fracção de classe, o foco analítico central dos diversos trabalhos sociológicos de Pierre Bourdieu.

3 A sociologia da individuação à maneira como a concebe Martuccelli (2006, 2010a) não faz uma leitura do social a partir das posições dos agentes no espaço social, mas parte dos indivíduos e das suas existências sociais para fazer uma análise macrossociológica. A grande questão de Danilo Martuccelli é a de que tipo de sociedade fabrica que tipo de indivíduos. É uma sociologia que reconhecendo a pluralidade das existências individuais numa mesma situação de classe ou numa mesma categoria profissional, procura fazer a compreensão sociológica de uma determinada singularidade societal, dando uma importância central ao sentir, pensar e agir dos indivíduos, sendo a leitura à escala macro o seu objectivo fundamental. Também em nenhum momento do texto consideramos que a individuação não é resultado do processo de socialização. Pelo contrário e ainda de acordo com a proposta de Danilo Martuccelli, é isso que nos faz convocar a obra de Norbert Elias A Sociedade dos Indivíduos (2004) que nos demonstra que a própria percepção dos "indivíduos" como separados disso a que chamamos "sociedade" é o produto de um processo longo de construção social, de fabricação sócio-histórica e de configurações de interdependência, em que no contínuo "nós-eu", 
as sociedades modernas passaram tendencialmente e historicamente a dar primazia ao "eu" em detrimento do "nós", o que não se passava nas sociedade pré-modernas em que o "nós" prevalecia na percepção dos indivíduos sobre o "eu". A individuação resulta de um processo de socialização de longo curso em que, por exemplo, a invenção dos modernos Estados-Nação, a afirmação dos direitos de propriedade individuais e dos direitos de propriedade social (Castel e Haroche, 2001) foram determinantes para a afirmação progressiva da autonomia dos indivíduos e que em décadas recentes este movimento se acelerou dando lugar na literatura sociológica a visões sociológicas em que predominam a sociedade de risco, sociedade líquida, sociedade em rede ou sociedade de consumo. Não se trata de fazer a análise de um indivíduo associal reduzido a uma concepção biologicista e inata, coisa que ele nunca o foi e nunca o será, mas fazer uma análise do social à escala individual, sabendo nós que o indivíduo é sempre socialmente constituído e que as provas e os desafios que enfrenta no mundo social são sempre marcadas diferencialmente a partir das diferentes posições de classe, de género, da etnicidade, de uma dada categoria profissional, do seu capital económico e cultural e dos diferentes suportes e recursos que os indivíduos são possuidores, entre outras variáveis importantes que importa levar em conta em cada situação empírica (Martuccelli, 2006). O que muda na sociologia da individuação é o enfoque colocado na análise, o que não é o mesmo que recusar a ideia de que os indivíduos são sempre marcados pelo seu processo de socialização, mas sim colocar o indivíduo e a sua construção social no centro da análise. Isso é feito de formas diferentes nas diferentes sociologias do indivíduo e desde logo nas diferentes sociologias que aqui escolhemos como ilustração, a sociologia à escala individual e a teoria do actor plural de Bernard Lahire, a sociologia da experiência de Dubet e a sociologia da individuação de Martuccelli. Três modos diferentes de dar inteligibilidade ao social à escala dos indivíduos.

4 O conceito de individuação, tal como o concebe Danilo Martuccelli na sua sociologia da individuação, difere do conceito de individualização, tal como o concebe Ulrick Beck. Como refere Martuccelli se "as sociedades contemporâneas são o teatro de um novo individualismo institucional que estandardiza fortemente, como Ulrick Beck bem o sublinhou, as etapas da vida", é preciso levar em conta que "este processo não passa pelo filtro de uma injunção única e comum de individualização, mas pelo contrário difracta-se por um número crescente de provas de diferentes tipos e natureza segundo os domínios e posições sociais. Dito de outra forma, é necessário construir operadores analíticos capazes, num só e mesmo movimento, de dar conta ao mesmo tempo de tendências simultâneas e contraditórias sobre a estandardização e a singularização" (Martuccelli, 2007, p. 74). Quando à ideia de sociedade singularista, recorremos mais uma vez aos trabalhos de Martuccelli, que nos diz que a expansão da singularidade no mundo actual é o resultado não voluntário, mas central de um conjunto díspar de processos estruturais. Martuccelli (2010a, p. 5) ilustra essa expansão com o exemplo do mundo da produção, que no apogeu da sociedade industrial funcionou como um dos principais factores de oposição à singularização. Sendo esse o período 
forte de estandardização dos produtos (Ford afirmava nos anos 1930 que os americanos podiam escolher o automóvel da cor que eles desejassem com a condição de que fosse preto), vivemos hoje em sociedades com tendência a des-estandardizar e mesmo a personalizar os produtos de consumo corrente. No mesmo sentido, são evidências de uma crescente singularização societal, as intervenções na área do trabalho social e da educação, de que o balanço de competências e a construção de portefólios reflexivos de aprendizagem no domínio dos processos de reconhecimento e validação de competências, no âmbito das políticas públicas de educação de adultos é um bom exemplo. Cada adulto realiza o seu balanço de competências individual e cada portefólio é um produto único e singular e não pode ser igual ao de qualquer outro; ou ainda as políticas públicas pensadas cada vez mais à medida, não só para determinadas categorias sociais, mas também de um trabalho que é exigido aos indivíduos em diversos domínios do social, sobre si próprios.

5 Para que não existam equívocos, importa esclarecer que não consideramos que a noção de socialização de Bourdieu derive directamente da noção de socialização de Durkheim. Enquanto em Durkheim (2004 [1893]) a noção de socialização resulta da incorporação da exterioridade social e da coercibilidade, bem presentes na sua definição de facto social; a noção de socialização em Bourdieu remete para o seu conceito de habitus, sendo este variável em função do lugar de classe ocupado pelos agentes na estrutura social. É conhecida a influência não só de Durkheim, mas também de Weber e de Marx na forma como Bourdieu conceptualiza não só o espaço social como também a leitura de como a interiorização das estruturas sociais resulta das lutas materiais e simbólicas que os agentes sociais levam a cabo nos diversos campos da vida social (Bonnewitz, 1998). Se em Durkheim há o predomínio de uma sociologia do consenso em que os indivíduos se procuram integrar de forma harmónica no todo social, isso não se passa de todo no caso da sociologia à la Bourdieu que abre espaço para uma sociologia do conflito.

6 Se a identidade individual prevalece nas sociedades ocidentais capitalistas contemporâneas sobre as identidades colectivas, tempos houve em que as transformações no equilíbrio nós-eu tendia para a identificação dos "indivíduos" às suas colectividades de pertença. A sociologia da modernidade também é fértil na demonstração em como a primeira modernidade contribuiu para a progressiva individualização do social e para a construção progressiva da autonomia dos indivíduos. Em Durkheim a passagem da solidariedade mecânica à solidariedade orgânica; em Tonnies, a passagem da comunidade à sociedade; em Simmel, a progressiva diferenciação social a partir da complexidade crescente dos círculos sociais (Martucelli e de Singly, 2012). Individualização essa, que a sociologia tem vindo a constatar, quer teórica, quer empiricamente.

7 A conexão aos contextos sociais na sociologia da individuação de Martuccelli (2006) é bem evidente numa das suas principais obras, Forgé par L'épreuve (2006), obra em que o autor põe a sua teoria à prova da empiria e demonstra como os indivíduos enfrentam as suas provações no mundo social, em domínios como a escolarização, o trabalho, a 
família, o território, a relação aos outros, a relação a si mesmo, a relação à História e às colectividades sociais. Nesta obra, Martuccelli demonstra como atravessando um conjunto de provas comuns a todos, os indivíduos enfrentam o social de forma diferencial, consoante a sua posição de classe, o género, a etnia, a categoria profissional, o tipo de família, os diferentes recursos e suportes que os indivíduos são capazes de mobilizar. Não recorrendo a um modo de inteligibilidade do social típico de uma sociologia posicional e partindo dos indivíduos e das suas existências individuais como forma de compreender a produção do social, Martuccelli não deixa nunca de os relacionar com os constrangimentos e os espaços de possibilidades com que se faz a sociedade. Nesse sentido, é a plasticidade e a maleabilidade aquilo que caracteriza a sua concepção do funcionamento do social.

\section{Referências}

Beck, U. (1992). Risk society: Towards a new modernity. Londres: Sage Publications.

Beck, U., e Beck-Gernsheim, E. (2002). Individualization: Institutionalized individualism and its social and political consequences. Londres: Sage Publications.

Bonnewitz, P. (1998). Premières leçons sur la sociologie de P. Bourdieu. Paris: PUF.

Boudon, R. (1977). Effets pervers et ordre social. Paris: PUF.

Bourdieu, P. (1979). La distinction. Paris: Les Éditions de Minuit.

Bourdieu, P. (1980). Le sens pratique. Paris: Les Éditions de Minuit.

Bourdieu, P., e Passeron, J.-C. (1964). Les héritiers, les étudiants e la culture. Paris: Les Édition de Minuit.

Bourdieu, P., e Passeron, J.-C. (1970). La reprodution. Eléments pour une théorie du système d'enseignement. Paris: Les Éditions de Minuit.

Castel, R., e Haroche, C. (2001). Propriété privée, propriété sociale, propriété de soi. Entretiens sur la construction de l'individu moderne. Paris: Fayard.

Castells, M. (2012). A era da informação: Economia, sociedade e cultura (Vol. 1). A sociedade em rede. Lisboa: Fundação Calouste Gulbenkian.

Corcuff, P. (1997). As novas sociologias. Construções da realidade social. Sintra: Vral.

Coulon, A. (1987). L'ethnométhodologie. Paris: PUF

Crozier, M., e Friedberg, E. (1977). L'acteur e le système. Les contraintes de l'action collective. Paris: Éditions du Seuil.

De Singly, F. (2006). Uns com os outros. Quando o individualismo cria laços. Lisboa: Instituto Piaget.

Dubet, F. (1996). Sociologia da experiência. Lisboa: Instituto Piaget.

Dubet, F. (2002). Le déclin de l'instituition. Paris: Éditions Du Seuil.

Durkheim, É. (1897). Le suicide. Étude sociologique. Paris: Félix Alcan.

Durkheim, É. (1967 [1894]). Les règles de la méthode sociologique. Paris: Les Presses Universitaires de France.

Durkheim, É. (2004 [1893]). De la division du travail social. Paris: Les Presses Universitaires de France. 
Elias, N. (2004). A sociedade dos indivíduos. Lisboa: Dom Quixote.

Giddens, A. (1998). As consequências da modernidade. Oeiras: Celta Editora.

Lahire, B. (2002). Portraits sociologiques. Paris: Editions Nathan.

Lahire, B. (2003). O homem plural. As molas da aç̧ão. Lisboa: Instituto Piaget.

Lahire, B. (2005). Patrimónios individuais de disposições: Para uma sociologia à escala individual. Sociologia, Problemas e Práticas, (49), pp. 11-42.

Lahire, B. (Dir.) (2013). Le travail sociologique de Pierre Bourdieu. Dettes e critiques. Paris: La Découverte.

Le Breton, D. (2004). L'interactionisme symbolique. Paris: PUF.

Lopes, J. T. (Org.) (2012). Registos do ator plural. Bernard Lahire na sociologia portuguesa. Porto: Edições Afrontamento.

Mills, C. W. (1997). L'imagination sociologique. Paris: La Découverte.

Martins, J. (2014). Das políticas às práticas de educação de adultos. Lógicas de acção, sentidos e modos de apropriação localmente produzidos. Lisboa: Colibri.

Martuccelli, D. (2005). Les trois voies de l'individu sociologique. EspacesTemps.net. Disponível em https:/ / www.espacestemps.net/articles/trois-voies-individu-sociologique/

Martuccelli, D. (2006). Forgé par l'épreuve. L'individu dans la France contemporaine. Paris: Armand Colin.

Martuccelli, D. (2007). La sociologie aux temps de l'individu. Revue pluridisciplinaire en sciences de l'homme et de la société, (5), pp. 65-84. Disponível em http:/ / www.revue-interrogations.org.

Martuccelli, D. (2010a). La société singulariste. Paris: Éditions Armand Colin.

Martuccelli, D. (2010b). Existen individuos en el Sur?. Santiago: LOM Editiones.

Martuccelli D., e de Singly, F. (2012). Les sociologies de l'individu. Paris: Armand Colin.

Marx, K., e Engels, F. (2008). O manifesto comunista. Lisboa: Padrões Culturais.

Parsons, T. (1977). Social systems and the evolution of action theory. Nova Iorque: Free Press.

Simmel, G. (1999). Sociologie. Paris: PUF.

Touraine, A. (1996). O retorno do actor. Ensaio sobre sociologia. Lisboa: Instituto Piaget.

Weber, M. (1971). Économie et société. Les categories de la sociologie. Paris: Librairie Plon.

Wright, E. O. (2013). Classes. Mangualde: Edições Pedago.

Data de submissão: 07/06/2019 | Data de aceitação: 29/07/2019 